\title{
sobre partos y nacimientos: derivas ético-políticas de la figura del "maestro- partero" en filosofía con/para niñxs ${ }^{1}$
}

\author{
julián macías ${ }^{2}$ \\ universidad de buenos aires, buenos aires, argentina \\ orcid id: https:/ / orcid.org/0000-0001-7574-8126
}

Maestro de la verdad

No deja de amonestar. Hace sabio los rostros ajenos, Hace a los otros tomar una cara,

Los hace desarrollarla.

Les abre los oídos, los ilumina.

Es maestro de guías, Les da su camino,

De él uno depende.

Pone un espejo delante de los otros, Los hace cuerdos y cuidadosos, Hace que en ellos aparezca una cara.

Gracias a él, la gente humaniza su querer $Y$ recibe una estricta enseñanza.

Hace fuertes los corazones, conforta a la gente, ayuda, remedia, a todos atiende. ${ }^{3}$

\section{resumen}

En este trabajo pretende hacer una revisión de las consecuencias ético-políticas de la metáfora de "maestro-partero" adjudicada a Sócrates en Teeteto y revalorizada por diferentes estudiosos para describir la función y el rol docente en Filosofía con/para niños. Para ello, el trabajo es dividido en tres secciones: en (1) se realiza un abordaje de la figura socrática en el diálogo Menón y se retoma la crítica de Jacques Rancière en El maestro ignorante y de la cual se hace eco Walter Kohan en el campo específico de Filosofía con/para niños. A continuación, (2) se recorren diferentes descripciones del rol docente en Filosofía con/para niños haciendo hincapié en los elementos que son revalorizados de la figura

\footnotetext{
1 He adoptado la utilización de la " $x$ " para visibilizar un problema que aún no está zanjado respecto a las marcas de género en en lenguaje escrito y oral, y que es necesario que siga siendo pensado. La " $x$ " en nuestro imaginario simbólico representa lo desconocido, la incógnita, $y$ en ese sentido con cada " $x$ " buscamos que quien lee recuerde que allí hay una cuestión para pensar, una decisión para tomar, y no una decisión tomada. En lo que atañe a las citas textuales se ha respetado la marca de género que lx autorx o traductorx haya adoptado. Para el caso de "maestro-partero" deliberadamente se ha adoptado la formulación en masculino para dejar en claro la apropiación socrática de un oficio restringido principalmente a las mujeres en la antigüedad. Si bien en este trabajo no se analizan las derivas de este proceso de apropiación, no debe pasarse inadvertido que un análisis complementario de este aspecto en torno a la figura de "maestro-partero" puede enriquecer las conclusiones en torno a las consecuencias ético-políticas de esta figura. Para más detalle véase nota 12 de este trabajo.

2 E-mail: jmacias@uba.ar

${ }^{3}$ Códice Matritense de la Real Academia, edición de Del Paso y Troncoso, vol. VIII, fol. 118, recto.
} 
sobre partos y nacimientos: derivas ético-políticas de la figura del "maestro-partero" en filosofía con/para niñxs

socrática. Para Matthew Lipman una de las claves para convertir las aulas en comunidades de investigación filosófica, era modificar sustancialmente el rol docente. En virtud de esto, y de que en sentido estricto lx docentx no debería enseñar en sentido tradicional, se han buscado diferentes metáforas para describir su rol. Hecho esto, en la sección (3), y sobre la hipótesis de que la descripción del docente como "guía" es asimilable a muchos rasgo que caracterizan a Sócrates, analizo en profundidad la metáfora del "maestro-partero" estableciendo los nexos con los desarollado en (1) y (2). Resulta interesante reflexionar en torno a las consecuencias ético-políticas al equiparar a quien enseña con un "maestropartero", sobre todo si se tiene en cuenta la descripción completa que realiza Platón en Teeteto y los rasgos que son tomados explícitamente en el corpus de Filosofía con/para niños. Finalmente, se sugiere una imagen diferente para describir el rol docente tomando como clave el concepto de natalidad de Hannah Arendt. De acuerdo al análisis realizado en el presente trabajo, espero poder mostrar la radical diferencia que implica tomar al nacimiento desde la perspectiva socrático-platónica respecto a la de Arendt.

palabras claves: natalidad; docente; parto; arendt; sócrates.

\section{sobre nascimentos e partos: derivas ético-política da figura do "proffesor-parteiro" na filosofia com/ para crianças.}

\section{resumo}

Neste trabalho, se pretende rever as conseqüências ético-políticas da metáfora de "professor-parteiro" atribuída a Sócrates em Teeteto e revalorizada por diferentes estudiosos para descrever a função e o papel dos professores na Filosofia com/para crianças. Para este fim, o trabalho é dividido em três seções: em (1), é feita uma abordagem da figura socrática no diálogo Menón e as críticas de Jacques Rancière em O Maestro Ignorante são retomadas, ecoadas por Walter Kohan no campo específico da Filosofia com/para crianças. Em seguida, (2) são revisadas diferentes descrições do papel do professor na Filosofia com/para crianças, enfatizando os elementos que são reavaliados da figura socrática. Para Matthew Lipman, uma das chaves para transformar as salas de aula em comunidades de pesquisa filosófica era modificar substancialmente o papel dos professores. Por causa disso, e porque a o professor não deve ensinar no sentido tradicional, diferentes metáforas têm sido buscadas para descrever seu papel. Tendo feito isto, na seção (3), e na hipótese de que a descrição do professor como "guia" é assimilável a muitos dos traços que caracterizam Sócrates, analiso em profundidade a metáfora do "professor-parteiro", estabelecendo as ligações com aqueles desenvolvidos em (1) e (2). É interessante refletir sobre as conseqüências ético-políticas de equiparar um professor a um "professor-parteiro", especialmente se levarmos em conta a descrição completa de Platão em Teeteto e as características que são explicitamente retomadas no corpus de Filosofia com/para crianças. Finalmente, uma imagem diferente é sugerida para descrever a função docente tomando como chave o conceito de nascimento de Hannah Arendt. De acordo com a análise feita no presente trabalho, espero mostrar a diferença radical implícita ao nascer da perspectiva socrático-platônica com respeito à Arendt.

palabras claves: natalidade; professor; parto; arendt; sócrates. 
on childbirths and births: ethical-political derivations of the figure of the "teachermidwife" in philosophy with/for children

\section{abstract}

In this paper, I endeavor to evaluate the ethical-political consequences of the metaphor of "teacher-midwife" awarded to Plato's Socrates in Theaetetus and its use by different scholars to describe the role of teacher in a Philosophy with/for children (Pf/wC) context. The paper is divided into three sections: first (1) an approach is made to the figure of Socrates in Meno, to the critique of his method as expressed by Jacques Rancière in The Ignorant Schoolmaster, and to the echoing of that critique by Walter Kohan in his evaluation of the pedagogy of $P f / w C$. Next, (2) different descriptions of the teacher's role in $P f / w C$ are reviewed, emphasizing the elements that emphasize the Socratic figure. For Matthew Lipman, one of the keys to turning classrooms into communities of philosophical inquiry was to substantially modify the teaching role. Because, on Lipman's account, the teacher should not teach in the traditional sense, different metaphors have been sought to describe her role. In section (3), I argue that a description of the teacher as "guide" can be applied to many features that characterize Socrates. I analyze in depth the metaphor of the "teachermidwife" establishing the links with those developed in (1) and (2). Emphasis is placed on the ethical-political consequences of equating the teacher with a "teacher-midwife", especially if we take into account Plato's complete description of pedagogical maiusis in Theaetetus, and the centrality of the metaphor in $\mathrm{P} / \mathrm{w} \mathrm{C}$ pedagogical practice. Finally, I consider the very different image of the "birth" metaphor that is suggested by Hannah Arendt's concept of "natality," and explore its implications for a pedagogical alternative to the Socratic.

keywords: natility; teacher; childbirth; arendt; socrates. 
sobre partos y nacimientos: derivas ético-políticas de la figura del "maestro-partero" en filosofía con/para niñxs

sobre partos y nacimientos: derivas ético-políticas de la figura del "maestropartero" en filosofía con/para niñxs

\section{introducción.}

Si bien el mismo Lipman se encarga de señalar su oposición con Platón respecto a la incompatibilidad entre la filosofía y lxs niñxs, para ambos la importancia de una educación filosófica para un proyecto ético-político es insoslayable. En Thinking in education (2003) Lipman afirma que la comunidad de investigación filosófica es garantía de una "democracia investigativa". Apoyándose en Dewey crítica a la democracia liberal, a la que califica de "simulacro", y propone una "comunidad investigativa" en la que democracia y racionalidad sean dos caras de la misma moneda:

En este sentido, podemos considerar la democracia como una idea reguladora para el desarrollo de la estructura social, mientras que la racionalidad es una idea reguladora para el desarrollo de la estructura de carácter, ya sea del ciudadano individual o de un procedimiento particular de una sociedad. (2003, p. 204)

En cuanto a Platón, la República, diálogo paradigmático en cuanto a la utilización de la educación como herramienta política privilegiada, enlaza de manera inquebrantable a la educación con la política y la ética. La educación platónica tiene como objetivo principal acercar el modo de vida de los ciudadanos al modo de vida filosófico personificado por Sócrates para que esto repercuta en una constitución política sana y armoniosa.

Por su parte, la figura de Sócrates no sólo marca un quiebre en la vida del mismo Platón. Como veremos a continuación, muchxs autorxs lo han tomado como ejemplo contrario a los "maestros de la verdad", cuya descripción platónica se asemeja mucho al docente retratado en los versos citados supra del Códice Matritense de la Real Academia. Sócrates, sin lugar a duda, ha marcado un antes y un después en lo que atañe a qué significa enseñar y cómo se debe enseñar.

Con el paso del tiempo, Sócrates se ha erigido como modelo de maestrx a seguir. No sólo por ser maestrx que guía aprendicxs, sino un maestro que guía a "maestrxs"4. En el campo de filosofía con o para niñxs (FcpN de ahora en adelante), su

\footnotetext{
${ }^{4}$ De la extensa bibliografía que analiza de manera detallada a los "maestros de verdad" desde la perspectiva platónica, se recomiendan especialmente Detienne (1988). En la fundación de la nueva
} 
figura ha sido revalorizada desde el inicio de la propuesta por Matthew Lipman y Ann Sharp y, en la actualidad, explícitamente por Oscar Brenifier5, para describir y caracterizar el modo en que se debe coordinar una comunidad de investigación filosófica.

A su vez, encontramos quienes han juzgado críticamente la pedagogía socrática. Quizás el caso más significativo es el análisis contracorriente que Jacques Rancière le dirige en El maestro ignorante. Allí lo califica, sin atenuantes, como "maestro embrutecedor" (2007, pp. 46-48) y lo ubica en las antípodas del "maestro emancipador" retratado en la figura de Jacotot. En efecto, Rancière sostiene que en el episodio de Sócrates con el esclavo de Menón en el diálogo homónimo, al tiempo que se demuestra el saber de Sócrates, se demuestra la impotencia intelectual del esclavo, concluyendo que: "Sócrates interroga a un esclavo destinado a seguir siendo esclavo" (2007, p. 47). Respecto a $F_{c p N}$, la crítica ranceriana es retomada fuertemente por Walter Kohan quién señala las consecuencias éticas y políticas de una pedagogía socrática (2009). En la misma línea que Rancière, para Kohan el problema de este tipo de pedagogías es que perpetúan una relación de inferioridad y desigualdad entre quien enseña y quien aprende $(2009$, p. 90)

En este trabajo, me interesa volver sobre la figura de Sócrates ${ }^{6}$, pero para analizar su caracterización como "partero" presente en Teeteto. La hipótesis de la cual parte mi análisis es que, de las tres imágenes ${ }^{7}$ con las que suele caracterizarse

ciudad, Platón elabora una severa crítica a todos aquellos que eran calificados de sabios (poetas, sofistas, retóricos, políticos) y opone la figura de filósofo encarnada en la figura de Sócrates.

5 Como veremos a continuación, muchxs estudiosxs retoman algunas características de la práctica filosófica-educativa de Sócrates. No obstante, Oscar Brenifier hace de Sócrates, no sólo un punto de referencia para la práctica docente, sino que lo considera como "el" modelo a seguir. Para un desarrollo de la propuesta de Brenifier en clave socrática consultar Filosofar como Sócrates: Introducción a la práctica filosófica (1997).

6 El presente trabajo retoma en análisis de la crítica a Sócrates planteada en Menón realizada en Educación y política en filosofía con niños y niñas. Reflexiones a partir de El maestro ignorante de Rancière (Macías, 2015). En dicho trabajo, me interesaba particularmente analizar los alcances de la crítica ranceriana al Sócrates del Menón para reflexionar en torno a si la propuesta de Rancière y la de Lipman efectivamente planteaba una relación diferente a la de Sócrates con el esclavo de Menón. Más allá de que en el Menón se reflexiona específicamente sobre el binomio enseñanza-aprendizaje, el hecho de que la paradoja de Menón se resuelva con la postulación platónica de la teoría de la reminiscencia ("conocer es recordar") puede vincularse con el reconocimiento de Platón de los límites del método socrático.

${ }^{7}$ Las tres imágenes a las que hacemos referencia aparecen en Apología de Sócrates, Menón y Teeteto. En Apología Sócrates se compara a sí mismo con un tábano: "un caballo grande y noble pero un poco lento por su tamaño, y que necesita ser aguijoneado por una especie de tábano, según creo, el dios 
sobre partos y nacimientos: derivas ético-políticas de la figura del "maestro-partero" en filosofía con/para niñxs

el rol pedagógico de Sócrates, la de "partero" es la que más se asemeja a la descripción del rol docente como guía o facilitador en $F c p N$ a tal punto que algunos retoman explícitamente esta imagen (Brenifier, 1999; García Moriyón, 2011).

Para fundamentar esta tesis, dividiré el texto en tres partes: (1) la primera se centrará en el Menón. Dicho diálogo interesa particularmente a este trabajo por dos motivos: el primero es que allí Sócrates y Menón dialogan en torno a las condiciones de posibilidad de enseñar y aprender, y se pone en duda a Sócrates como figura de maestro-guía en el conocimiento. Por otra parte, la respuesta de Sócrates al desafío de Menón se produce mediante la ejemplificación del rol de Sócrates en una conversación con un esclavo cuyo único signo de igualdad con Sócrates y Menón es el hecho de hablar griego. Este rol, no sólo tiene paralelos con la descripción de "partero" de Sócrates de Teeteto, sino que también es el puntapié inicial para la crítica ranceriana a Sócrates.

Hecho esto, (2) en la segunda sección recorreré diferentes caracterizaciones de docente en Filosofía con/para niñxs. Partiendo del hecho de que desde sus inicios se buscó ubicar al docente en un rol diferente al de la enseñanza tradicional, me interesa recuperar algunas imágenes que se han utilizado para describrirlx y detenerme finalmente en la caracterización de maestrx-guía que tiene explícitos antecedentes en la figura de Sócrates como "maestro-partero".

Por último, (3) realizaré un análisis crítico de la descripción como "partero" de Sócrates presente en la descripción de maestrx-guía. Para ello, tomaré como eje el concepto de natalidad que Hannah Arendt utiliza para reflexionar en torno a la educación en "La crisis de la educación" (2016a) y, en un plano más general, para

me ha colocado junto a la ciudad para una función semejante, y como tal, despertándoos, persuadiéndoos y reprochándoos el uno a uno, no cesaré durante todo el día de posarme en todas partes" (30e-31a). En Menón, en cambio, la calificación de "pez torpedo" procede en un enojado Menón en los siguientes términos: "Y ahora, según me parece, me estás hechizando, embrujando y hasta encantado por completo al punto que me has reducido a una madeja de confusiones. Y si se me permite hacer una pequeña broma, diría que eres parecidísimo, por tu figura como por lo demás, a ese chato pez marino, el torpedo" (80a). Puede observarse que en estas dos representaciones prevalece la función destructiva de Sócrates pretende descolocar a sus interlocutores y correrlos de la comodidad del aparente saber. En el caso de la última imagen, en cambio, Sócrates se autorretrata en una faceta más constructiva a decir de sí mismo que es como "una partera". Esta imagen la analizaremos más en detalle en la tercera sección, pero puede encontrarse en Teeteto, 150a-151c. En cuanto a las traducción, en el caso de Menón se sigue a Olivieri, F. J. (trad.) (2007) Platón. Menón. Madrid: Gredos. En cuanto a Teeteto se utiliza Vallejo Campos (trad.) (2006) Platón, Teeteto. Buenos Aires: Losada. 
reflexionar en torno a lo que nos caracteriza como seres humanos en La condición humana (2016a). Como espero poder mostrar, la idea de "nacimiento" que subyace a la propuesta de Arendt permitiría resignificar la figura de "maestro-partero" y con ello avanzar en una caracterización del rol docente en Filosofía con/para niñxs que no reproduzca las relaciones ético-políticas que el propio Lipman busca modificar.

\section{sócrates, "maestro embrutecedor".}

A pesar de que en República encontramos un desarrollo detallado de la propuesta educativa, el Menón plantea numerosas cuestiones en torno a la posibilidad de conocer y de enseñar, así como también desarrolla la caracterización de "maestro-guía" a través del episodio con el esclavo de Menón.

Al comenzar a leer dicho diálogo, encontramos a Menón interrogando a Sócrates acerca de si la virtud tiene la cualidad de enseñarse/aprenderse mediante la práctica o si, por el contrario, es una cualidad que se tiene por naturaleza o se obtiene de algún otro modo (70a). No obstante, como es su costumbre, Sócrates se niega a responder porque para él no es posible hablar acerca de cómo es algo (si la virtud es enseñable o no) antes de saber qué es algo:

(...) $Y$, de lo que ignoro qué es, ¿de qué manera podría conocer precisamente cómo es? ¿O te parece que pueda haber alguien que no conozca por completo quién es Menón y sea capaz de conocer si es bello, rico y también noble, o lo contrario de estas cosas? ¿Te parece que es posible? (Platón, Menón, 71a-b)

Este es el punto de partida para la discusión entre ambos. En los sucesivos pasajes, Menón ofrecerá diferentes respuestas a la pregunta de Sócrates y éste se encargará de refutarlas una por una. Así, tras varios intentos frustrados por responder qué es la virtud, Menón se encuentra entorpecido y sin saber qué contestar (80a):

¿Y de qué manera buscarás, Sócrates, aquello que ignoras totalmente qué es? ¿Cuál de las cosas que ignoras vas a proponerte como objeto de tu búsqueda? Porque si dieras efectiva y ciertamente con ella, ¿cómo advertirás, en efecto, que es ésa que buscas, desde el momento que no la conocías? (Platón, Menón, 80d)

Si bien Sócrates lo acusa de entretejer un argumento erístico (Menón, 80e), lo interesante es que la aporía de Menón es compatible con la negativa socrática de 
sobre partos y nacimientos: derivas ético-políticas de la figura del "maestro-partero" en filosofía con/para niñxs

referirse a cómo es la virtud, sin saber primero qué es. En efecto, esta negativa presente al comienzo del diálogo que niega la posibilidad de conocer cómo es algo o alguien sin saber en absoluto de su existencia conduce al planteo de Menón que retoma este punto. Menón está cansado del juego socrático y luego acusarlo de ser como el pez torpedo que "entorpece al que se le acerca y lo toca" (80a), ha escuchado a Sócrates reconocer su ignorancia respecto a qué es la virtud (80c). ¿Para qué seguir la conversación si, aunque llegara a buen término, no podrían saberlo?

Este planteo nos interesa especialmente porque lleva al límite la postura socrática y lo pone a prueba en un sentido realmente filosófico y, a su vez, pedagógico. Desde el punto de vista filosófico, el cuestionamiento de Menón pone en jaque la misma práctica socrática de la filosofía, puesto que para Sócrates es necesario reconocer la propia ignorancia (que no se sabe) para poder comenzar el camino filosófico.

Por otra parte, pedagógicamente se abren los siguientes interrogantes: ¿es posible conocer algo si no se lo conoce en absoluto ${ }^{8}{ }$ Es posible enseñar sin conocer en absoluto aquello que se "enseña" o es necesario que haya alguien que conozca sobre aquello que se enseña para que otrx aprenda?

Con este planteo, Menón cuestiona la posibilidad misma de enseñar y aprender, pues pone de manifiesto los límites del desconocimiento absoluto sobre aquello que se enseña previo a la actividad de enseñanza tal como hace Sócrates (70b). ¿En qué medida es posible un "maestro ignorante", tal como propone Rancière (2007) a través de la figura de Jacotot? Desde la perspectiva de Menón, si se ignora absolutamente algo, no es posible siquiera iniciar la búsqueda por aquello que no se sabe y menos aún encontrarlo. Ello justifica la necesidad de unx maestrx

\footnotetext{
8 En Menón, la aporía es planteada en términos "absolutos". Esto quiere decir que quien aprende no sabe nada en absoluto sobre eso que aprende. En este aspecto, Menón es fiel al modo en que Sócrates plantea las condiciones para iniciar la búsqueda, pues si ni Menón ni Sócrates conocen "en absoluto" eso que buscan, entonces no podrán darse cuenta de que lo han encontrado, aunque lo tengan delante de sus narices. Como consecuencia, la respuesta de Platón es que nunca estamos en un desconocimiento absoluto, en tanto nuestra alma antes de encarnar en el cuerpo ha conocido "todas las cosas" (81c). Entiendo que esta respuesta que incluye Platón no solamente apunta a refutar a Menón, sino que también cuestiona el principio de ignorancia que plantea Sócrates. En este sentido, resulta relevante reflexionar en torno a qué grado de saber se posee previamente a una relación de enseñanza-aprendizaje y en qué consiste el pasaje del no-conocimiento al conocimiento en términos pedagógicos.
} 
que sepa, previamente, aquello que se va a aprender/enseñar, y que pueda, como Platón muestra en el famoso "episodio del esclavo", preguntar de manera variada y repetida a su interlocutor.

Precisamente con relación a este punto, Rancière se coloca en las antípodas del planteo de Menón. Así, encontramos que en El maestro ignorante, el filósofo francés opone a la enseñanza propia del sistema explicador, la "enseñanza universal" (2007, p. 31). A diferencia de la enseñanza tradicional que supone una diferencia asimétrica y jerárquica entre quien enseña y quien aprende, la "enseñanza universal" elimina esta distinción sobre la base de la igualdad de las inteligencias (2007, p. 28).

Asimismo, mientras que en la crítica de Menón subyace el presupuesto de que en todo proceso de conocimiento/aprendizaje debe haber un saber previo poseído por quien enseña (pues en tal caso, quien lo posee podría darse "cuenta de haberlo alcanzado"), en el caso de Rancière parecería eliminarse tal condición pues, en sus propias palabras "no es necesario saber algo para enseñar y es posible enseñar lo que se ignora" (2007, p.34).

De ahí la crítica a toda la enseñanza tradicional, explicadora, entre la que encontramos a la socrática: la pedagogía embrutecedora puede llevarse a adelante por "métodos duros y suaves, tradicionales o modernos, pasivos o activos, cuyo rendimiento puede ser comparado" (2007, p. 29), pero todos poseen en común la transmisión de conocimiento del maestro al alumno como fin de la actividad pedagógica. Incluso Sócrates, cuyo famoso "sólo sé que no se nada" podría equipararse, a primera vista, con el "no tengo nada que enseñarles" (2007, p. 30) ranceriano, cometería este error. Para el pensador francés, en cada maestro explicador duerme un Sócrates, que pregunta para instruir y al interrogar, pregunta para demostrar su saber y la impotencia de quien aprende.

A diferencia de toda la educación tradicional (y explicadora), Rancière destaca que el mérito de la educación universal propuesta por Jacotot en su experiencia en la Universidad de Lovaina, es el haber "retirado su inteligencia del juego, permitiendo que la inteligencia de sus alumnos se enfrentará con la del libro" 
sobre partos y nacimientos: derivas ético-políticas de la figura del "maestro-partero" en filosofía con/para niñxs

(2007, p. 28). Esta es la condición que permite que el alumno se emancipe y verifique la igualdad de su inteligencia con la de los demás.

Ahora bien: a partir de las reflexiones de Rancière en torno a Sócrates podríamos preguntarnos si el corrimiento de lx maestrx es posible o si nos llevaría a una aporía, tal como se plantea en el Menón. Además de tensionar las relaciones entre conocimiento, enseñanza y aprendizaje, entre enseñante y aprendiz, estas cuestiones nos permiten reflexionar en torno al lugar que ocupa el docente en la propuesta de $F c p N$. En los términos en los que lo coloca Rancière, no es posible escindir las acciones de quien enseña de una serie de relaciones ético-políticas ${ }^{9}$ que condicionan la relación entre docentxs y estudiantxs, entre estudiantxs con el objeto de saber y la figura docentx como propietarix de ese saber (Kohan, 2009, pp. 87102). En este sentido, en el próximo apartado recuperaremos algunas de las figuras en torno al rol docente más recurrentes en la bibliografía de $F c p N$ a fin de mostrar los elementos socráticos que encontramos en dichas caracterizaciones.

\section{caracterización del rol docente en filosofía con/para niñxs.}

Desde sus inicios, la propuesta de Lipman pretendió constituir una ruptura con el rol atribuido tradicionalmente a lxs docentxs. Así, motivadxs por la búsqueda de descripciones y caracterizaciones que reflejaran esa ruptura, se han realizado diversas estrategias para dar cuenta de la especificidad de su función. Una de las más frecuentes consiste en definirlo como "coordinador". Para López, por ejemplo, la tarea de quien coordina es la de:

conducirlos [a los participantes] hasta ese abismo donde los sentidos se pierden y los clichés se deshacen, donde las palabras pierden su evidencia cotidiana (...) quien coordina una experiencia de filosofía deberá escuchar cada palabra como por primera vez y

\footnotetext{
9 Walter Kohan ofrece otros argumentos para reforzar la crítica ranceriana a través del análisis de ciertos pasajes de Eutifrón y Cármides. Lo interesante de análisis de Kohan respecto a lo dicho por Rancière es que la lupa está puesta, no en el contenido de lo que enseña, sino en la forma en la cual enseña. Esto nos remite otra vez a la cuestión de si en la enseñanza forma y contenido puede escindirse, o si en rigor el contenido de la enseñanza en precisamente la forma: "Lo que está en juego es la política de pensamiento que afirma en su relación con los otros, qué espacio ocupa para sí. Qué espacio deja para los otros en el pensamiento, qué cosas permite pensar y qué cosas no dejar pensar; qué fuerzas desata en el espacio del pensamiento habitado por sus interlocutores, qué potencias desencadena o interrumpe en su dialogar con otros" (2009:102).
} 
buscará que cada una de ellas sea pronunciada como si fuese la primera vez. $(2008$, p. 84$)$

Desde esta perspectiva, quien coordina, a diferencia de quien enseña, no se refugia en un corpus de saber que debe enseñar o trasmitir a lxs niñxs. Se encuentra principalmente en posición de escucha, más que de dadorx de conocimientos. En esta línea encontramos a Cecilia Caputo (1997), quien retoma la idea de Heidegger de "dejar aprender" para dar cuenta de la posición docente en la propuesta de $F c p N$ :

La tarea del docente de Filosofía con niños no es para nada la de dirigir. Su función es la de coordinar la investigación y aventurarse en ella junto con sus alumnos. Con lo cual, lo que hace no es trabajar para ellos sino con ellos (...) El docente no puede enseñar si el mismo no está aprendiendo. (1997, p. 277)

Para Cecilia Caputo, otro rasgo del rol docente como "coordinador", es que para enseñar es necesario estar aprendiendo. Esto resignifica el rol docente en tanto implica un rol extremadamente activo de moderación que consiste en preguntar, escuchar y poner en relación aquello que se va diciendo.

De esta manera, llegamos a otra figura recurrente que es la del "moderador o árbitro" que enfatiza el rol vinculado a la distribución de la palabra y pretende dar lugar a la aparición de las voces de lxs niñxs. ${ }^{10} \mathrm{Su}$ origen se remonta hasta los orígenes de la propuesta Philosophy for children en la medida que lxs docentxs, en palabras Lipman, se diferencia de lxs niñxs, más por sus funciones, que por su diferencia de jerarquía:

los chicos están allí para filosofar, para desarrollar su propia experiencia de pensamiento; los docentes, para acompañar y ayudarlos a lograrlo. Son los niños quienes plantean problemas, proponen hipótesis y las contrastan. Así, ponen en juego herramientas ligadas a las dimensiones críticas, creativas y cuidadosas de los otros, van construyendo su pensamiento propio (1992, p. 175)

\footnotetext{
${ }^{10}$ En Filosofía con los más pequeños, Gustavo Santiago enumera algunas metáforas acerca del papel del docente, así como también algunas que ejemplifican lo que no es un docente. Cada una de estas imágenes pone de manifiesto ciertos rasgos del quehacer docente y se presentan, no es un sentido excluyente sino más bien complementarios. Así, según Santiago, el docente sería como "un árbitro, que cuida que se respeten ciertas reglas de juego", como "un instrumentista, que cuida que estén a disposición las herramientas necesarias para realizar la tarea", como un "entrenador, que propone actividades y ejercicios que les permitan a los participantes rendir al máximo en el momento de realizar la tarea" o como "un director de orquesta, que se empeña por lograr que cada individuo pueda ensamblarse armónicamente con los demás para producir algo que cada uno por su cuenta no podría lograr" (2002, p. 54-55).
} 
sobre partos y nacimientos: derivas ético-políticas de la figura del "maestro-partero" en filosofía con/para niñxs

Otra cuestión importante gira en torno al grado de participación docente en una comunidad de investigación filosófica. Lipman, por ejemplo, ya en La filosofía en aula (1992) admitía que todas las actitudes de un profesor tienen un peso en lxs niñxs. Asimismo, Ann Sharp considera que la clave para evitar el adoctrinamiento y para fomentar la libre participación de sus participantxs, no radica en la no participación docente en el plano conceptual sino en el modo, en cómo se produce esa participación:

(...) no hay nada de malo en los intentos de persuasión, siempre que: i) estos intentos sean en sí mismos razonables y éticos, y ii) quienes hayan de ser persuadidos tengan tanto la capacidad y libertad de responder con sus propias técnicas persuasivas, preguntas, argumentos y contraejemplos, como de tomar sus propias decisiones (1996, p. 187)

Esta descripción acerca a lxs docentxs a la figura de guía o facilitador que está estrechamente asociada al concepto de modelo. En La filosofía en el aula (1992, p. 170), Lipman establece algunos lineamientos que definen el rol docente en la comunidad de investigación filosófica. El docente funciona como modelo de lxs niñxs en lo referido al comportamiento que manifiesta y a la apreciación de la discusión filosófica. En la misma línea, Splitter y Sharp adhieren a esta idea, al afirmar que "el docente, como modelo del proceso de indagación, tiene la especial responsabilidad de guiar a sus alumnos y asistirlos de manera de no trastocar o minar sus propias iniciativas" (1996, p. 191)

Esta imagen de "docente-modelo" como guía o facilitador nos remite directamente a la figura de Sócrates. Martha Nussbaum, en su libro Sin fines de lucro. Por que la democracia necesita de las humanidades, introduce la propuesta de Lipman y Matthews en una línea de pedagogías que inician con Sócrates e incluyen figuras como Rousseau, Pestalozzi, Froebel, Pestalozzi, Dewey, Tagore, entre otrxs (2010, pp. 74-111). Según la estudiosa estadounidense, Matthew Lipman impulsó una propuesta socrática, no autoritaria que coloca a lxs niñxs en una posición activa. Esta caracterización, por su parte, se debe en gran medida a que el mismo Lipman revaloriza la figura de Sócrates y su método para colocarlo como modelo docente a seguir. Pero, ¿cuáles son los elementos que Lipman recupera de la figura de Sócrates? 
En La filosofia en el aula, Lipman, Sharp y Oscanyan afirman que Sócrates es la gran figura que sirve de modelo para hacer filosofía, pues lo que "Sócrates nos enseña no es a saber filosofía, ni aplicarla, sino a practicarla" (1992, p. 30). Lo valioso de la propuesta socrática es que encarna a la filosofía como una actividad, como un hacer y una forma de vida.

Otro rasgo importante es la primacía del diálogo y, paralelamente, la importancia del "continuo ejercicio de la investigación filosófica siguiendo el razonamiento hasta donde nos lleve" (1992, p. 33). Tal como señala Kennedy (2004), la suma importancia del diálogo llevó a Lipman y Sharp a extender aquella práctica realizada de manera solitaria a una práctica colectiva tal como se produce en el marco de una comunidad de investigación filosófica:

La síntesis de Lipman y Sharp reconstruyó la filosofía como una actividad comunitaria y dialógica. Así concebida, la comunidad de investigación filosófica es una recapitulación de la práctica socrática con una diferencia importante y determinante (...) el proceso deconstructivo/reconstructivo que Sócrates asume únicamente sobre sí mismo se distribuye entre todos los miembros y tiene su fuente en sus interacciones (2004, p. 746)

La propuesta de Lipman, al igual que la de Sócrates, está centrada en el diálogo como mayéutica. García Moriyón destaca que este procedimiento va acercando a lxs interlocutorxs a un "mayor rigor conceptual" (2011, p. 17) y recupera la influencia de Socratic Method and Critical Philosophy de Leonard Nelson en la propuesta de Lipman. ${ }^{11}$ En palabras de García Moriyón, "el maestro deja de ser tal y pasa a convertirse en facilitador, una figura que puede recordar a la de Sócrates como partero de la verdad" (2011, p. 21). Esta metáfora también la podemos leer en Filosofar como Socrates: introduccion a la practica filosófica de Oscar Brenifier:

La forma en que Sócrates producía este impacto cognitivo en sus interlocutores era a través del cuestionamiento, incitándoles a descubrir su propia incoherencia e ignorancia, un proceso con el que las personas podían dar a luz nuevos conceptos: la mayéutica. (1999, p. 33)"

\footnotetext{
${ }^{11}$ Para un desarrollo de la influencia de Nelson en la propuesta de Lipman, puede consultarse Davey Chesters (2012) quien equipara el concepto de "comunidad de investigación" de Lipman con el de "diálogo socrático" de Nelson y analizan los vínculos entre ambas propuestas.
} 
sobre partos y nacimientos: derivas ético-políticas de la figura del "maestro-partero" en filosofía con/para niñxs

Ser docente en FcpN significa, desde esta óptica, facilitar cierta práctica filosófica que se asemeja a "dar a luz nuevos conceptos". De lo dicho hasta aquí observamos que la revalorización de la figura de Sócrates se vincula con su rol de guía, de acompañante de un proceso dialógico. En virtud de esto, observamos que, dentro de las metáforas que suelen describir la labor docente de Sócrates mencionadas al comienzo de nuestro trabajo, es la figura del partero la que más encuadra con el rol docente como "guía" o "facilitador" en FpcN. En próximo apartado me dedicaré a analizar con mayor profundidad las consecuencias éticopolíticas de esta imagen.

\section{sócrates, "maestro-partero".}

Volvamos un instante al Menón. Ante la problemática planteada por su interlocutor sobre cómo avanzar en el conocimiento, tanto para buscar aquello que se desconoce como para distinguir cuando se haya encontrado algo (80d), Sócrates pide que traiga a su esclavo. Lleva a cabo el famoso interrogatorio por medio del cual Platón "muestra" que en rigor la ignorancia no proviene del desconocimiento absoluto sino de haber olvidado lo que nuestra alma conoció antes de encarnar en un cuerpo. Allí, el rol de la figura de Sócrates en el método mayéutico es clave.

Este procedimiento no se produce sin ironía en el Menón. En efecto, al tiempo que Sócrates afirma que el aprendizaje (descritos en términos de reminiscencia) se produce "sin que nadie le enseñe, sino por ser interrogado" (85d) puesto que "yo no le enseño nada, sino que le pregunto todo" (82e), señala el rol protagónico del maestro pues es necesario "preguntar esto muchas veces y de diferentes maneras" (85c). En este punto es que debemos recordar la advertencia de Rancière:

Sócrates debe llevar al esclavo de la mano para que éste pueda encontrar aquello que ya estaba en él. La demostración de su saber es al mismo tiempo la de su impotencia: nunca avanzará por su cuenta y, por otra parte, nadie le pide que lo haga, sino para ilustrar la lección del maestro. Sócrates interroga a un esclavo destinado a seguir siendo esclavo. (2007, p. 47) 
En esta descripción, son marcadas los paralelos con Teeteto, diálogo en el cual el método mayéutico está asociado a la labor de las parteras (150a-151c) ${ }^{12}$ y donde es posible rastrear interesantes paralelos con Menón. Observamos que en Teeteto Sócrates también describe su arte como un interrogatorio (150c) por medio del cual “jamás aprenden nada de mí, sino que ellos por sí mismos descubren y dan a luz muchas cosas nobles" (150d-e). Tal como en Menón, Sócrates niega su rol como maestro al mismo tiempo que afirma ser el responsable de los resultados del parto (150e).

Y no sólo eso: Walter Kohan (2013) ha señalado que, en la descripción del trabajo de las parteras, Platón menciona la necesidad de utilizar fármacos (149c). Lo interesante es que el significado de phármakon ${ }^{13}$ es doble, pues puede referir tanto a veneno como a remedio: la diferencia entre uno y otro radica en la cantidad dada por quien administra la dosis. Al igual que una partera tiene el poder de aliviar o provocar dolor en el parto, quien enseña también puede manejar las dosis del phármakon. En este punto, vale recordar que Brenifier señala la importancia del docente como administrador del grado de dolor de ese "parto" en la práctica filosófica: “Algo parecido al pánico puede extenderse con cierta prontitud. Por esta razón, es importante que establezcamos diversos tipos de anestesia epidural para conseguir un "parto" menos doloroso" (1997, p.136).

La imagen del "maestro-partero" nos remite a una concepción de maestrx como actor imprescindible. A través de sus intervenciones el "maestro-partero" no sólo generará las condiciones de posibilidad para ese nacimiento, sino que además será garante de que ese nacimiento deseable se produzca y el modo en que ese parto

\footnotetext{
12 En cuanto al significado simbólico de esta caracterización de Sócrates como "partero" en Teeteto y Las Nubes de Aristófanes, Mariana Gardella señala que "en la tradición mítica griega, la función de la maternidad es usurpada y convertida en una metáfora para explicar la capacidad de creación del varón. La fantasía de la procreación masculina se utiliza como metáfora del poder de producción simbólica del varón cuya alma preñada atraviesa un parto intelectual" (2020, p. 95). Para un análisis de las diversas representaciones de la maternidad, los partos y los nacimientos en el mundo grecolatino, véase Las mujeres en la Antigüedad. Partos, maternidades y nacimientos (2020).

${ }^{13}$ El término griego phármakon adquiere un significado ambivalente. Por un lado, puede significar remedio, pero por otro también puede hacer mención a un veneno. Lo interesante es que la caracterización positiva o negativa dependerá del uso que se le dé, y mientras el ignorante no puede controlar los efectos debido a su falta de conocimiento, es el experto quién podrá hacer el mayor bien o el mayor mal. En la metáfora del "maestro-partera" el conocimiento de su uso recae en el maestro, quien decide y administra su dosis, reforzándose así su poder respecto a quien aprende.
} 
sobre partos y nacimientos: derivas ético-políticas de la figura del "maestro-partero" en filosofía con/para niñxs

ocurrirá (doloroso o no) dependerá de su potestad. De modo análogo que lo que ocurre con el esclavo de Menón, sin la intervención del "maestro-partero", los aprendices no serían capaces de "dar a luz".

A raíz de lo dicho anteriormente, podemos observar que la situación de poder escondida detrás de la ironía de la ignorancia que Rancière denunciara en el caso del Menón, también es palpable en el Teeteto. Parafraseando a Rancière, la función del "maestro-partero" es verificar el parto, que en la esfera educativa es asimilable al proceso de aprendizaje. En efecto, además de ser guiados por quien enseña (recordemos la descripción del docente como guía en $F c p N$ ), esx mismx maestrx (o sea, Sócrates) será quien juzgue si esos vástagos (conocimientos) son deseables o no: "lo más importante de mi arte es que es capaz de poner a prueba, por cualquier medio, si la mente del joven engendra una imagen y una falsedad, o algo fecundo y verdadero" (150b-c).

Es decir, es lx maestrx quién evalúa si esa idea o pensamiento es correcta o no. Esa calificación dependerá de un criterio de verdad que se desprende, en el marco de los diálogos platónicos, del ámbito eidético. Las Ideas en tanto modelos permiten determinar si esos "vástagos" son falsos o verdaderos, nobles o desechables. En el plano dialógico, Sócrates determinará si aquello que dice ese aprendiz es una verdad o meramente una opinión (dóxa).

Este esquema aplicado al ámbito educativo, que se sigue de recuperar la figura de Sócrates como "maestro-partero", tiene riesgosas consecuencias. Porque en toda práctica educativa en la que quien enseña determina si un pensamiento es verdadero o correcto, subyace un modelo que sirve como criterio para determinar su carácter. Continuando con la metáfora del partero, en la medida en que "el verdadero trabajo de fabricación se realiza bajo la guía de un modelo de acuerdo con el cual se construye el objeto" (Arendt, 2016a, p. 161), la calidad del vástago será definida por la exactitud con la cual esa copia reproduce el modelo original propuesto por el docente". 


\section{reflexiones finales: por una docencia de la natalidad.}

Llegado a este punto, resulta interesante recuperar algunas ideas de Hannah Arendt14, a la cual muchxs estudiosxs han definido como la filósofa de la natalidad.15 En La condición humana, Arendt distingue tres actividades fundamentales: la labor que está vinculada con todos los aspectos biológicos, el trabajo, reflejado en todo aquello que es artificial (no natural) y que es producido por los seres humanos, y la acción, la actividad entre los seres humanos sin mediación alguna. A cada una de estas actividades, le corresponde una condición humana específica: la vida a la labor, la mundanidad al trabajo y la pluralidad a la acción (2016a, p. 21-22)

De estas tres esferas, me interesa detenerme en la acción, esfera en la cual “con la palabra y acto nos insertamos en el mundo humano" (2016a, p. 201) y que es definida por Arendt como "un segundo nacimiento". Para Arendt este segundo nacimiento es el verdadero nacimiento y su importancia radica en tanto ofrece la oportunidad de responder a la pregunta primordial:

Acción y discurso están tan estrechamente relacionados debido a que el acto primordial y específicamente humano debe contener al mismo tiempo la respuesta a la pregunta planteadas a todo recién llegado: ¿quién eres tú? (2016a, p. 202)

Lo interesante de esta pregunta es que, si bien su respuesta va a adquirir sentido en la medida en que entre en relación con otras personas (pluralidad), dicha respuesta no podrá ser nunca juzgada. No hay lugar en este esquema para un "maestro-partero" que juzga si ese nacimiento es deseable o si debe ser purgado. Como nos recuerda Arendt: "en la propia naturaleza del comienzo radica que se inicie algo nuevo que no puede esperarse de cualquier cosa que haya ocurrido antes" (2016a, p. 201).

\footnotetext{
${ }^{14}$ Hannah Arendt considera que Sócrates es la última figura en la cual política y filosofía confluyen. Desde entonces, la tradición iniciada por Platón escindió estas dos esferas por completo hasta la actualidad. Arendt desarrolla este punto y otros vinculados a la figura socrática en La promesa de la política (2015). En el capítulo dedicado por completo a Sócrates, analiza también las tres metáforas de su rol docente desde una perspectiva política, abordadas en detalle en Arendt and Socrates (1999) por Dana Villa. Si bien el tratamiento arendtiano de Sócrates no fue inicialmente este, me propongo análisis la figura del "maestro-partero" a partir de la noción de natalidad que Arendt desarrolla como concepto fundamental de su filosofía.

${ }^{15}$ La filosofía de Hannah Arendt es compleja y puede ser abordada desde múltiples ángulos, pero la noción de natalidad, opuesta a la idea platónica de filosofía como práctica para la muerte, es un concepto central. En el presente trabajo, hemos acudido a textos que abordaran este concepto desde la perspectiva de la educación, en especial Bárcena (2006), Bárcena y Mèlich (2014) y Nixon (2020)
} 
sobre partos y nacimientos: derivas ético-políticas de la figura del "maestro-partero" en filosofía con/para niñxs

Esto implica un quiebre por completo con la idea de modelo, y con ello la imagen de partero tal como retrata Platón a Sócrates. El modelo es aquello que antecede, que es copiado o reproducido. Y esta idea de "reproducción", que tiene connotaciones también en el plano biológico del nacimiento, es precisamente la que está presente en el concepto de fabricación que Arendt separa del campo de la acción. Al respecto, Bárcena y Mèlich señalan que la idea de educación como fabricación es lo que caracteriza a la educación clásica y recuperan estas palabras de La condición humana: "El verdadero trabajo de fabricación se realiza bajo la guía de un modelo, de acuerdo con el cual se construye el objeto" (2014, p. 161).

En consecuencia, Bárcena y Mèlich concluyen que una educación que se funda en la idea de modelo toma a la educación como medio para alcanzar la reproducción de ese modelo. Prevalece, como mencionamos antes, la imitación como procedimiento sin la cual ese proceso educativo no alcanza su finalidad. Desde esta lógica, la pregunta originaria, “¿quién eres tú?”, trae consigno en su misma enunciación la respuesta: "sé como yo", "defínete cómo yo lo hago".

En lo que atañe a Arendt, el esquema que encontramos en La condición humana adquiere su traducción pedagógica en La crisis de la educación. Para Arendt, la esencia de la educación es la natalidad (2016b, p. 271), condición humana que genera el advenimiento de nuevas generaciones a un mundo siempre "viejo" para ellas en la medida de que ese mundo es siempre anterior a "los nuevos". La conclusión, basado en un análisis estructural de la educación, es que esa crisis proviene de una tradición que se remonta a Platón y que tiene su profundización a partir de Rousseau.

Para Arendt, el error de Platón no sólo fue haber hecho de la educación un instrumento político, un medio para expulsar a "los viejos" del nuevo estado utópico, sino algo mucho peor: “a los niños, a los que se les quiere educar para que sean ciudadanos de un mañana utópico, en realidad se les niega su propio papel futuro en el campo político" (2016b, p. 274).

En lo que atañe a la idea moderna que inicia con Rousseau y que considera la educación como un instrumento político por excelencia, Arendt hace hincapié en el hecho de que la educación no puede basarse en el principio de reproducción del 
mundo viejo ni en la idea de que, con la llegada de esas nuevas generaciones, un nuevo mundo comienza. Es decir: no se trata de repetir, ni imitar el mundo compartido, como si este mundo fuera un modelo que reproducir, ni de desecharlo o desestimarlo (2016b, p. 273). Para Arendt, este mundo es siempre compartido, un entre, que se erige como espacio común entre adultxs y niñxs y, específicamente en la escuela, como espacio común entre maestrxs y alumnxs. Para ella la clave reside en un análisis que remite a:

la relación entre las personas adultas y los niños en general o, en para decirlo en términos más generales y exactos, nuestra actitud hacia la natalidad, hacia el hecho de que todos hemos venido al mundo al nacer y de que este mundo se renueva sin cesar a través de los nacimientos. (2016, p. 301)

Sobre esta base no hay lugar para la metáfora del "maestro-partero", pues este tipo de maestrx quita la posibilidad a esxs niñxs de renovar el mundo al que llegan en tanto establece una relación de reproducción repetitiva más que una construcción novedosa ${ }^{16}$. Quizás la metáfora que mejor represente las ideas de Arendt sea la del "maestrx huésped", maestrx que recibe a esxs niñxs en un mundo propio, que lo cuida y, por sobre, que habilita la posibilidad de una construcción novedosa e imprevisible:

También mediante la educación decidimos si amamos a nuestros hijos lo bastante como para no arrojarlos de nuestro mundo y librarlos a sus propios recursos, ni quietarles de las manos la oportunidad de emprender algo nuevo, algo que nosotros no imaginamos. (2016b, p. 247)

La potencia de esta idea de "maestrx húesped" para describir el rol docente en $F c p N$ radica en que ubica al docente en un espacio-tiempo caracterizado por el entre. No es quien recibe para llevar a un lugar que ya conoce, o para que alcancen cierto modo de ser esperable, sino que ofrece esas coordenadas para proporcionar un nacimiento mutuo, desconocido previamente tanto para quien aprende como para quien enseña:

\footnotetext{
${ }^{16}$ La novedad en Hannah Arendt adquiere sentido a la luz de lo dicho en La condición humana. Para ella, lo novedoso se vincula con lo originario en tanto arché, comienzo de algo que no estaba antes: "Actuar, en su sentido más general, significa tomar una iniciativa, comenzar (como indica la palabra griega archein, comenzar, conducir y finalmente gobernar), poner algo en movimiento (que es el significado original del agere latino" (2016a:201)
} 
sobre partos y nacimientos: derivas ético-políticas de la figura del "maestro-partero" en filosofía con/para niñxs

“El hijo no es simplemente obra mía, como un poema o un objeto fabricado; tampoco es una propiedad. Ni las categorías de poder ni las del tener son capaces de indicar la relación con el hijo. Ni la noción de causa ni la de propiedad permiten captar el hecho de la fecundidad. A mi hijo no lo tengo sino que, en cierto modo, lo soy" (Emanuel Levinas citado en Bárcena; Mèlich, 2016, p. 98).

En suma: desde esta perspectiva unx alumnx nunca puede ser una obra, como un poema o un objeto fabricado, un producto nacido de una relación de enseñanza-aprendizaje tal como establece la metáfora del "maestro-partero" retratada en los textos analizados en torno a la figura de Sócrates. En este sentido, entendemos que es necesario revisar la concepción de Matthew Lipman que toma al docente como modelo a ser imitado ya que, como afirman Kohan-Waskman, "la idea de modelo, como sustentación de la práctica pedagógica, tal vez sea inconveniente en términos de una educación que afirme la autonomía como principio y fin". (2000, p. 34). Como hemos mostrado a lo largo del trabajo, el concepto de "natalidad" arendtiano permite colocar al docente en un rol activo que permita la aparición de lxs alumnxs de manera novedosa, evitando así la lógica de reproducción repetitiva que caracteriza a la educación tradicional y a la metáfora del maestro-partero.

\section{referencias}

Arendt, H. (2016a) La condición Humana. Buenos Aires: Paidós.

Arendt, H. (2016b) "La crisis de la educación" en Arendt, H. (2016) Entre el pasado y el futuro. Ochos ejercicios sobre reflexión politica. Barcelona: Ariel.

Bárcena, F. (2006) Hannah Arendt: una filosofía de la natalidad. Barcelona: Herder.

Bárcena, F. y Mèlich, J-C. (2014) La educación como acontecimiento ético. Natalidad, narración y hospitalidad. Buenos Aires: Miño y Dávila.

Brenifier, O. (1999) Filosofar como Sócrates: Introducción a la práctica filosófica. Valencia: Diálogo.

Caputo, C. (1997) "Pensar la tarea docente" en Kohan, W. y Waksman, V. (comps) (1997) Qué es Filosofía para Niños: Ideas y propuestas para pensar la educación. Buenos Aires: Oficina de Publicaciones del CBC - UBA

Davey Chesters, S. (2012) The Socratic Classroom. Rotterdam: Sense Publishers.

Detienne, M. (1988) Los maestros de la verdad en la Grecia arcaica. Madrid: Taurus.

Gardella, M. (2020) "La maternidad de la palabra. Nosis de Locri y el parto de la lengua" en Sonna, V. (compiladora) (2020) Las mujeres en la Antigüedad. Partos, maternidades y nacimientos. Buenos Aires: Editorial Teseo, pp. 93-117. Disponible en versión electrónica en https:/ / www.teseopress.com/lasmujeresenlaantiguedad

García Moriyón (2011) "Filosofía para niños: genealogía de un proyecto" HASER. Revista Internacional de Filosofía Aplicada, n 2, 2011, pp. 15-40

Kennedy, D. (2004) "The Role of a Facilitator in a Community of Philosophical Inquiry". Metaphilosophy 35(5): 744-65. 
Kohan, W. (2009) Sócrates. El enigma de enseñar. Buenos Aires: Biblos.

Kohan, W. (2013) "Plato and Socrates: From an Educator of Childhood to a Childlike Educator?" Stud Philos Educ 32:313-325.

Kohan, W. y Waksman, V. (comps.). (2000) Filosofía para niños. Discusiones y propuestas. Buenos Aires: Noveduc.

Lipman, M. (2003). Thinking in Education. Cambridge: Cambridge University Press.

Lipman, M., Sharp, A., Oscanyan, F.(1992) La Filosofía en el Aula. Madrid: Ed. De la Torre

López, M. (2008) Filosofía con niños y jóvenes. La comunidad de indagación a partir de los conceptos de acontecimiento y experiencia trágica. Buenos Aires: Ediciones Novedades Educativas.

Macías, J. (2015) “Educación y política en filosofía con niños y niñas. Reflexiones a partir de El maestro ignorante de Rancière" en Análisis : revista colombiana de humanidades, $\mathrm{N}^{\circ}$. 86, pp. $69-84$

Nixon, J. (2020) Hannah Arendt. The Promise of Education. London: SpringerBriefs.

Nussbaum, M. (2010) Sin fines de lucro. Por qué la democracia necesita de las humanidades. Buenos Aires: Katz.

Olivieri, F. J. (trad.) (2007) Menón Madrid: Gredos.

Rancière, J. (2007). El maestro ignorante: cinco lecciones sobre la emancipación intelectual. Buenos Aires: Del Zorzal.

Santiago, G. (2002) Filosofía con los más pequeños. Buenos Aires: Noveduc.

Splitter, L.- Sharp, A. (1996) La otra Educación: Filosofía para Niños y la Comunidad de Indagación. Buenos Aires: Manantial.

Vallejo Campos (trad.) (2006) Teeteto. Buenos Aires: Losada.

Villa, D. R. (1999) “Arendt and Socrates", Revue Internationale de Philosophie, JUIN, Vol. 53, No. 208 (2).

recibido en: 15.09.2020

aprobado en: 06.06.2021 